\title{
CITIZEN SCIENCE DESIGN THE ROLE OF PRODUCT DESIGNERS: A STUDY CASE, INSECTIVOROS
}

\author{
Francisco Javier SERÓN TORRECILLA \\ Escuela Superior de Diseño de Aragón (ESDA, Zaragoza, Spain)
}

\begin{abstract}
User-centred approaches as a designer, as well as open design and citizen science present challenges for our students in setting up their competences. In recent years, our School of Design has endeavoured to incorporate proposals close to these movements, which come from local and national agents working in contexts of greater social and environmental complexity. The research, supported by a case study, has served to contrast the following hypothesis: there is a change in the role of our students in this type of approach that broadens their capacities, leading them to become mediators and facilitators in the framework of Citizen Science Design projects. The article has been organised as follows, a brief introduction on the background of the project and the research, a description of the project and above all of the changes observed in its role, to end with a discussion of the results in relation to the theoretical framework. The last point is dedicated to the conclusions, pointing out the need to examine in greater depth these projects that seem to have a positive impact on the skills of our product students.
\end{abstract}

Keywords: Citizen Design Science, product design, action-research design

\section{INTRODUCTION AND RESEARCH BACKGROUNDS}

The research arises from the development of a project promoted by Ibercivis (Citizen Science Foundation) in agreement with the city council in the academic year 2017/2018. Our institution is linked to the project from the design of an smart birdhouse together with several collectives, volunteers, lay people and professionals from different disciplines. The initial objective was to be able to analyse with the object the presence of insectivores in the urban ecosystem by connecting to a local IoT network. A solution that arises from the need to solve a public health problem, the increase of insects in the urban environment. Since the beginning, it has been a context of interdisciplinary, co-participated and codesign work that for the students means learning and teaching centred on previous experiences that were established from other proposals such as the $\mathrm{CESAR}^{1}$ calls. During the first three months and with the guidance of the teacher and author of this article, some elements contributed by the different agents involved were incorporated from the subject of bionics. The change in the direction of the foundation prevented the continuation of the project. In a subsequent period, the achievements and changes observed among our students were evaluated being the backbone of the research considered as a second phase during the current academic year. The following are some of the issues analysed:

- The students reported their shortcomings in addressing interdisciplinarity in design, along with their difficulties in adapting to a project without a clear figure of coordination.

- They targeted the requirements of making decisions that were not exclusively design decisions.

The teacher's reflections and observations are reported in the form of questions:

- What actions do we need to introduce in order to prepare our students for this kind of projects related to present-day social complexity?

- Is it possible for our students to modify or enhance the role they play beyond product design?

${ }^{1}$ CESAR is the name for the Open-Lab belonging to the BIFI (Institute of bio computation of complex systems) and Universidad de Zaragoza (U.Z.) and hosted at ETOPIA-CAT. Every year CESAR launch different call for projects of citizen science, open-design and other propose of sharing knowledge. CESAR are configurated for a Sound, Wet'Lab ,Fab'Lab and Audio-visual Lab's. U.Z is partner of Ibercivis. 
Based on these shared reflections, and as described below, a new phase of the project was planned with the objective of contrasting a hypothesis. In approaches of this nature, students require new skills to shift from their role as product designers to one in which they mediate and facilitate processes.

\section{RESEARCH FRAMEWORKS}

Due to the nature of the proposal and the characteristics of the agents following a bibliographic review, a framework has been considered that is coherent in many respects with the so-called Citizen Design Science (hereafter CDS) see Figure 1 [1]. The experience has been focused on the analysis of a study case and the impact of these practices on the training and teaching of product designers in complex projects, and the type of competences that seem to be shown as changing the role and the importance for their professional future. On the one hand, Citizen Science (hereafter CS) is seen like participatory research that involves the society inform of voluntary [2,3]. In most cases, the participation of volunteers, professionals or not, is limited to analysing data that would otherwise be impossible on the part of academic or professional science [4]. But it is not the only form of CS participation. There are other models of co-created research that allow a social appropriation of new knowledge, but which have been less represented or studied in the literature [5], however much closer and coherent with the case here presented [6]. On the other hand, open-design and the greater access to digital manufacturing have introduced a change in the relationships between designers and users [7]. A change of professional domain is occurring which implies a change of a vision of the discipline for user-centred to user as designer $[8,9]$. In this sense, it has been affirming that the product designer will be in the future a mediator between the demands of the users and the technological changes that affect the society [10]. In a report made by the Mckinsey Global Institute, it was noted that by the year 2025 additive manufacturing along with the emergence of IoT would generate profound changes in design professionals, and therefore in design education. In the same way pointed out by Wierzoch (Artefact, 2015) the new technologies employed by the users will lead to a training in design to improve the skills to define problems through analysis, which in general is still a lack of our students [11]. Returning to the beginning, although CDS were born as ways of participation of citizenship in urban planning, it is perfectly extrapolated to the case of study by adjusting much of the items to its approach, as different authors have pointed out [12]. In addition, this approach allows us as a framework for action to assess the skills that our students will require in their professional future and attend to the roles the will play [13].

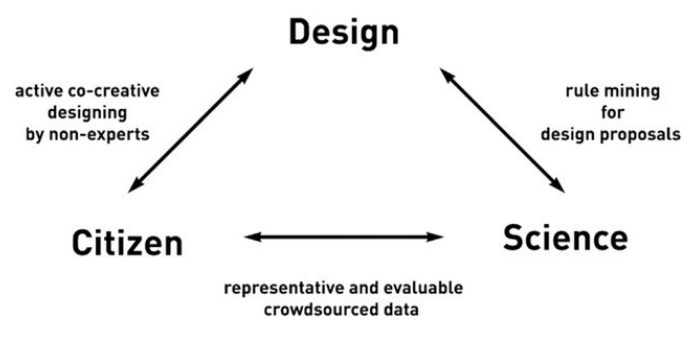

Figure 1. Citizen Design Science [1]

\section{CASE STUDY: BIRD-HOUSE MAKERS, DESIGNER AS MEDIATOR AND FACILITATOR}

In this point we summarise what the second phase has meant in relation to the role of the students in relation to the hypothesis. The steps are linked to the different agents and to the changes that have been introduced in the design to integrate this shared knowledge, taking into account how the role is modified. One of the fundamental aspects was the absence of a clear coordination. Although all the agents present a common objective, each of them enters the project with its specific objectives, which entails a task for the designers to serve each of these needs, biological, electronic, meteorological, and above all, what affected some very special users and participants, primary school students, a key factor in the project. Its role was to be that of design receptors from the personalisation in the assembly and conditioning, in addition to the rest of tasks related to the scientific project. In the first meeting, see Figure 2, we can already see the propositive attitude of the designers based on previous research[14], by pointing out the possibility of extending the analysis to other insectivores such as bats and geckos. 


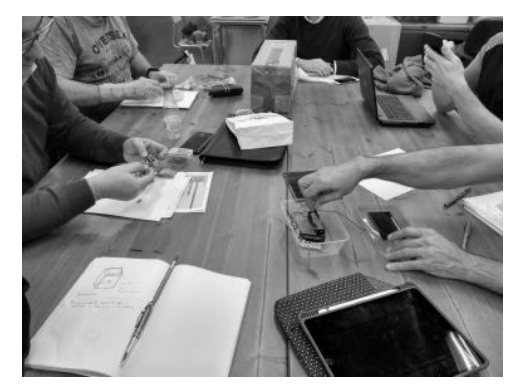

Figure 2. First meeting ESDA

During the first two months, decisions were taken to resolve difficulties regarding the coordination process of the agents involved. One of the fundamental aspects was to specify the role of schoolchildren and how this affected the design, considerations expressed by our students for their relevance to the success of the proposal. Figures 3 and 4 show the first virtual prototypes that include some of the agreed aspects.
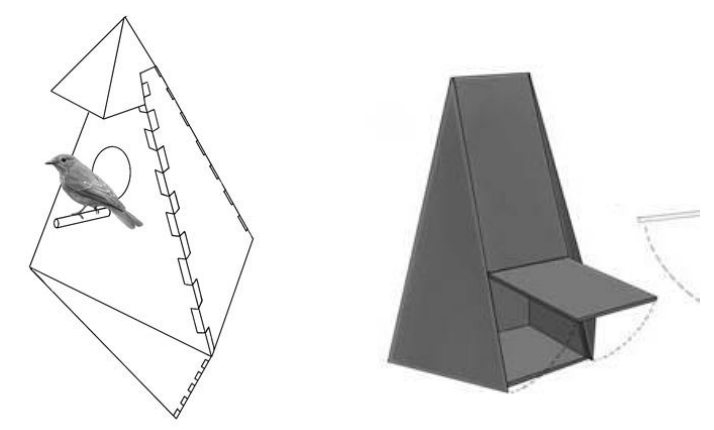

Figures 3, 4. Firsts sketches, 3 for birds, 4 for geckos

Figure 5, it can be valued a virtual prototype with some requirements that would later be replaced in the final object, for example solar panels, but that provided solutions and was adjustable to different species due to its modular character of interchangeable parts.

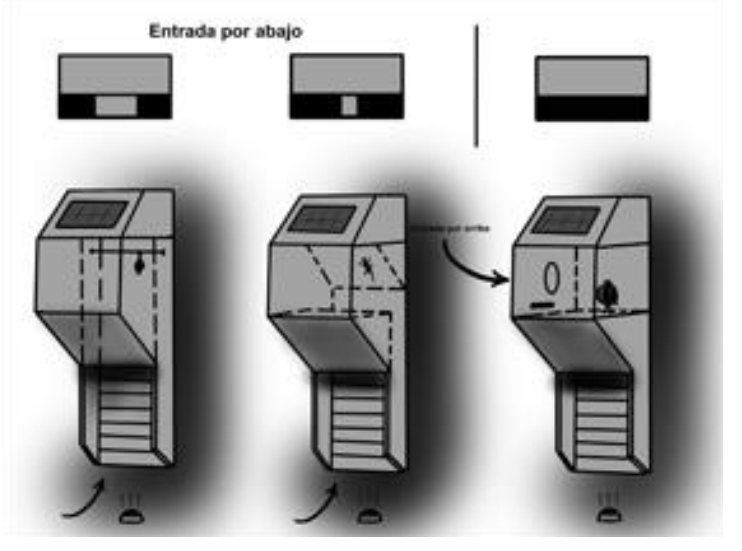

Figure 5. final prototype, bats, geckos and birds, modular system with interchangeable parts

Finally, Figures 6 and 7 show two material prototypes located (ESDA and a primary school) to test the sensors and the connection to the IoT network designed by volunteers in computer engineering and electronics. One of the most revealing moments to observe the role of our students took place in the workshop reported to more than 60 primary schools of the city. 

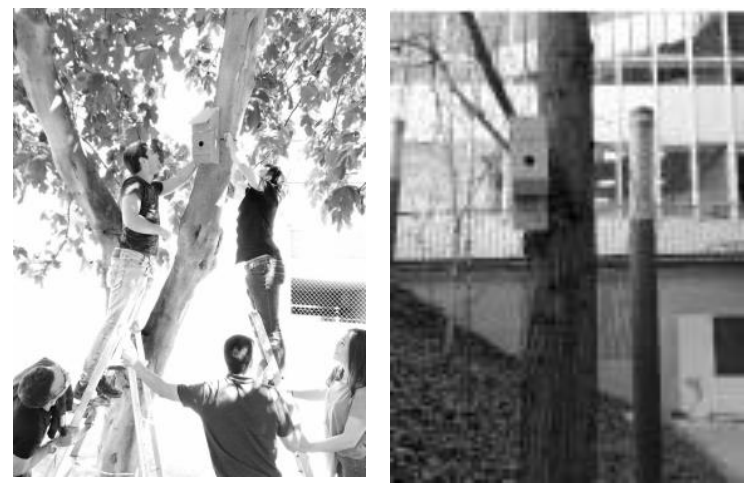

Figures 6, 7. Students placing a prototype in a first primary school. Right, ESDA

They encouraged primary teachers to participate with their scholars, both in the final design and in the further investigation, observing and analysing data from the app. It should be noted that in this case, except for a short introduction of the CS concept by Ibercivis, the meeting was chaired by the design students, Figure 8. Figure 9 shows the students' explanations to an elementary school teacher and the centre principal during the setup of the first smart house.
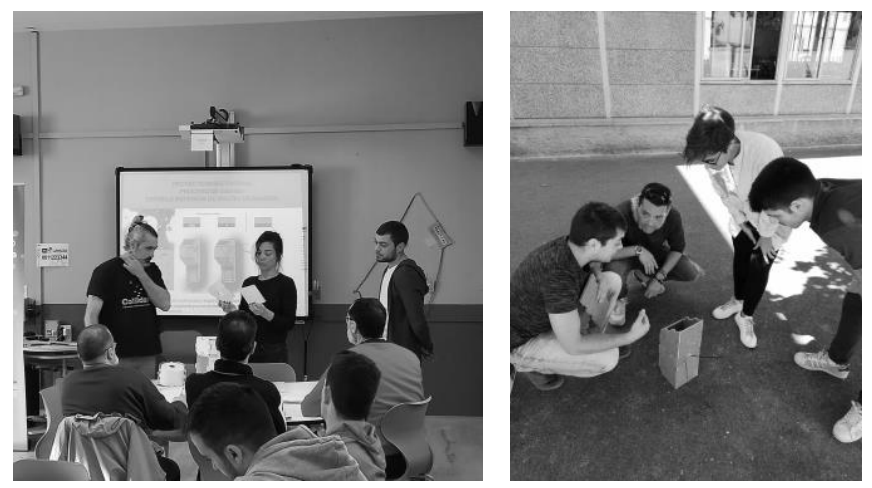

Figures 8, 9: Left, design students training centre, right primary school explaining

\section{RESEARCH METHODOLOGY AND OUTCOMES}

A participatory action approach based on a case study has been employed because of its link with the design processes in terms of reflection and because of its natural cycle for both researcher and students. see Figure 10.

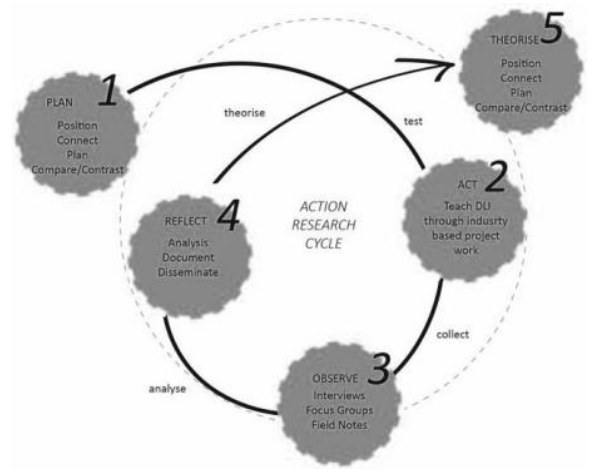

Figures 10. Action-research cycle according [15]

Various authors point out how these cycles of action-reflection expose what happens in the action of design and in the spaces of theoretical conceptualisation of learning[15]. The case study, by its participatory nature, cross-disciplinary, co-designed knowledge generator also serves reflection cycles, fostering interactions between the process, the design methodology and reflections [16,17] see Figure 11 [19]. 


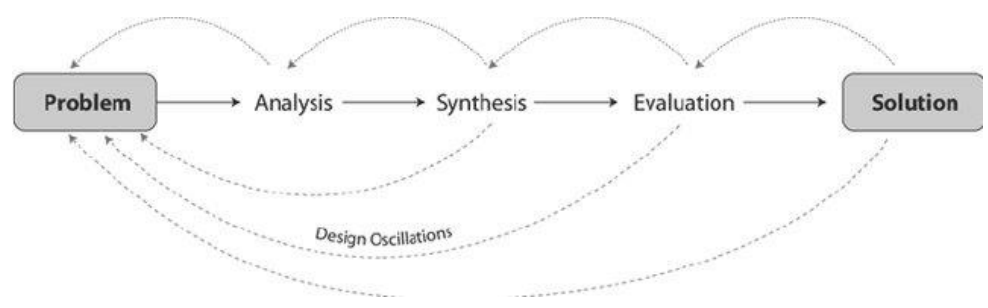

Figures 11. Design Cycle [19]

These are processes that are consistent with the information-gathering tools used to retrieve valuable information, despite the difficulties they present in reporting and establishing narratives [18]. These are complemented by other techniques such as focus groups and surveys that encourage self-reflection.

- Students have difficulties when handling projects of these characteristics without a plan.

- On the other hand, and despite the lack of confidence, they are able to take responsiblity in the success of the project which leads them to mediate in situations and facilitate encounters from their position in design, both the product and the communication strategies.

In the case of the reports, the information is consistent with the observed:

- "Sometimes the electronic part was not clear and that generated anxiety and we had to make decisions for the following stages" (Student 4)

- $\quad$ "In some way, when we have the opportunity to explain all the steps of the project everything seems to be orderly" (Student 1)

There are some statements that are linked to their degree of involvement:

- $\quad$ "In contrast with my classmates who did not come to these workshops I feel my role is coming further than a product designer" (Student 2)

Finally, collect the difficulties and challenges they assume when communicating and try to involve other agents of the project:

- "We had to integrate different aspects coming from stakeholders, electronic devices, IoT systems, biological requirements and forward the specfic features that it could need the scholars, $i$ think step by step we adopted a global perspective for doing it to communicate properly" (Student 3)

\section{DISCUSSION OF RESEARCH RESULTS}

An integrative view of teaching/learning in the context of product design is broadening the possibilities of incorporating students into projects such as those presented, requiring new competencies. As several authors $[6,8]$ have pointed out, coordinating decision making in CDS proposals [1] implies adopting roles beyond their role as designers, facilitating and mediating in the solution of problems $[9,10]$, as well as facilitating the interrelation between the different stakeholders. The reflections of the students, in spite of the difficulties in establishing them [18], seem to confirm these processes of integration. Although the nature of the project has raised doubts and insecurities, there has been an improvement in their communication and mediation skills, with the teacher's guidance, going beyond their role as designers. Those who have become more involved are those who have achieved more active roles. It is at this point that they see their role as facilitators in complex challenges with multiple agents. In any case, it is necessary to deepen this type of proposals investigating the evolution and adaptation to problems and solutions in complex contexts.

\section{CONCLUSIONS}

The conclusions drawn from a case study are always limited and the contrast of the baseline hypotheses should be taken with caution. In any case, it can be said that the results are in the sense of international research presented in the references regarding the role that product designers will play in the future as mediators and facilitators of processes. On the other hand, an investigation sustained on the development of a project of enormous complexity allows to present a sufficiently open and enriching scenario to analyse the tasks of our students. The results, despite the brevity of the article, seem to go in the same direction as the international research presented in the references, aimed at a commitment to open curricular competencies to a technological panorama in which this complexity, together with the present 
one in local contexts that presents issues such as health, the environment, and the loss of biodiversity, require a more active contribution from designers beyond their task as manufacturers of artefacts. It is therefore a matter of insisting once again on scenarios where multiple perspectives of enormous actuality, co-design, co-participated knowledge, etc. are converging, which will not only allow them to participate in the society of current knowledge but will also contribute to reflection on practice and education in design for the future.

\section{REFERENCES}

[1] Mueller J., Hangxin L., Chirkin A., Klein B. and Schmitt G. Citizen Design Science: A strategy for crowd-creative urban design. Cities, 2017, 72, 181-188.

[2] Hand E. Citizen science: People power. Nature, 2010, 466(7307):685-8.

[3] Gura T. Citizen science: Amateur experts. Nature, 2013, 20 496, 259-261.

[4] Cohn J.P. Citizen Science: Can Volunteers Do Real Research? BioScience, 2012,58, 3, 192197.doi.org/10.1641/B580303

[5] Delfanti A. Users and peers. From citizen science to P2P science. Cell, 2013, $21,01$. https://doi.org/10.1641/B580303

[6] Philips R. and Burley S. Open Design: Non-professional User-Designers Creating Products for Citizen Science: A case Study of Beekeepers. Conference Paper from book Design, User Experience, and Usabiliti. Web, Mobile, and Product Design: Second International Conference, DUXU 2013, Held as Part of HCI International 2013, Las Vegas, NV, US, July 21-26, 2013 pp.424-431), 2013.

[7] Gershenfeld N. How to make almost anything: The digital fabrication revolution. Foreign Affairs, 2012, 91, 6, 42-57.

[8] Lee Y. Design participation tactics: involving people in the design of their built environment. Doctoral thesis, 2007, School of Design, Hong Kong Polytechnic University.

[9] Manzini E. Design, When Everybody Designs: An Introduction to Design for Social Innovation MIT Press, 2015.

[10] Joyce Y. Connecting practice to research (and back to practice): making the leap from design practice to design research. Design Principles and Practices, 2007, 1(1), 81-90.

[11] Sennet R. Together, 2012, New Haven, CT: Yale University Press.

[12] O'Kane C. and Tully R. (2018). Towards a Truly Interdisciplinary Approach to Product Design Education. International Conference on Engineering and Product Design Education, London, United Kingdom, 6 \& 7 September 2018.

[13] Oygür I. and Ülkebas S.D. Students' product perception: a cross-sectional analysis. International Conference on Engineering and Product Design Education, London, United Kingdom, 6 \& 7 September 2018.

[14] National Bat Monitoring Programme (2018). London: https://www.bats.org.uk/ourwork/national-bat-monitoring-programme/reports/nbmp-annual-report

[15] Swann C. (2002). Action Research and the Practice of Design. Design Issues, 18(1), 49-61.

[16] Farel R., Hisarciklilar O., Boujut J.-F., Thomann G. and Villeneuve F. Challenges in expert user participation in design evaluation meetings. Journal of Design Research, Inderscience, 2013, 11 (2), pp.186-201.ff10.1504/JDR.2013.055155ff. ffhal-00856142f

[17] Blessing L. and Chakrabarti A. DRM, a Design Research Methodology, 2009 (Springer-Verlag London Limited)

[18] Yee J. (2007) Design education in the age of media convergence. In Engineering and Product Design Education (EPDE07), 13-14 September 2007, School of Design, Northumbria University, Newcastle-upon-Tyne.

[19] Jones J. Christopher. Design Methods. $2^{\text {nd }}$ ed. New York; London: Van Nostrand Reinhold: Chapman Hall, 1992. 